\title{
DOIS LADRÕES: A RECONFIGURAÇÃO DO ENREDO NO CONTO UM LADRÃO E EM MEMÓRIAS DO CÁRCERE, AMBos dE Graciliano Ramos
}

Cícera Jessiane Lins Santos ${ }^{1}$

DOI 10.11606/issn.1981-7169.crioula.2017.126058

RESUMO: Neste trabalho, busca-se discutir a diversidade de perspectivas utilizadas na execução de um enredo empregado em duas obras de Graciliano Ramos: "Um ladrão", conto pertencente ao volume Insônia, e um dos trechos de Memórias do cárcere. Para isso, adota-se uma perspectiva comparatista atrelada à crítica sociológica, a fim de perceber as possíveis relações do enredo com a conjuntura histórica e literária de então.

ABSTRACT: In this paper, we aim to discuss the diversity of perspectives employed in Graciliano Ramos' two literary productions' plot: "Um ladrão", a tale belonging to the volume Insônia; and na excerpt from the novel Memórias do cárcere. For this, a comparative perspective was adopted, considering a sociological critique, in order to perceive possible relations among the plot and the historical and literary conjunctures of the literary's production period.

PALAVRAS-CHAVE: Conto, Crítica sociológica; Literatura comparada.

KEYWORDS: Short story; Sociological critic; Comparative literature.

1 Mestranda em Letras pela Universidade Federal de São Paulo. Professora de Língua Portuguesa, na modalidade Educação de Jovens e Adultos (EJA), no nível Ensino Fundamental II, da rede municipal de educação de Santo André. 
segunda fase do Modernismo brasileiro é conhecida 4 por seu vínculo a questões sociais e maior participaE ção política. De acordo com Lafetá (2000), trata-se do momento de desenvolvimento do projeto ideológico, possibilitado, em parte, pela atuação dos escritores que empreenderam, inicialmente, o projeto estético. Graciliano Ramos figura entre os romancistas mais representativos desse segundo momento, embora a contragosto.

Vidas Secas (1938) foi o último romance composto pelo alagoano e contém elementos respectivos a vivências - suas e de outros -, esse aspecto, já presente em composições anteriores, tornou-se característica de sua criação literária e foi tratado de diferentes formas tanto em textos críticos - como "O fator econômico no romance brasileiro" (1945) e "Norte e Sul" (1937) -, quanto nos registros epistolares. Em carta ao jornalista João Condé, em junho de 1944, o romancista Ihe escreveu:

No começo de 1937, utilizei num conto a lembrança de um cachorro sacrificado na Maniçoba, interior de Pernambuco, há muitos anos. Transformei o velho Pedro Ferro, meu avô, no vaqueiro Fabiano; minha avó tomou a figura de Sinhá Vitória; meus tios pequenos, machos e fêmeas, reduziram-se a dois meninos (Arquivo IEB-USP Fundo GR-CA-06).

$\mathrm{E}$ as referências a um contexto, mesmo particular, persistiram. Há estudos que já indicaram esse diálogo entre os mundos ficcional e factual, tais como os de Candido (2006) e de Maia (2008). A recuperação de personagens, experiências 
e temas é corrente na obra do escritor e o elo comum entre esses fatores é a experiência vivida ou assistida por ele, carregada por uma reflexão e percepção não só subjetiva, mas também histórica da realidade, em que ele busca, na fundamentação verossímil do enredo, o "fator econômico" que ampara a tentativa de representação de um recorte da sociedade.

Em Ficção e confissão, Candido avalia: "Para Graciliano a experiência é condição da escrita" e "compreendemos que a experiência era para ele um atrativo irresistível; e que, sobretudo quando fonte de comoção da personalidade, não podia escapar à necessidade de fixá-la" (2006, p. 82). Em 1936, Graciliano Ramos vivenciou situações diversas em virtude da injusta prisão. Acredita-se que para um escritor que sempre expressou necessidade de relação com questões sociais, ele tinha em suas mãos e memória um importante material a explorar. Os relatos desse conturbado tempo foram publicados postumamente em Memórias do cárcere, em 1953. A respeito desta e de outras obras do romancista, podemos supor um estreitamento na abordagem dos relatos de vida, e não da sua apenas: do aparente afastamento destes em Caetés (1933), inaugural, até a sua concretização em Infância (1945) e Memórias do cárcere (1953).

Essa observação não se quer entender no sentido de que o trabalho do escritor seja resumido à reprodução de experiências, perspectiva que restringe suas realizações, mas sim na direção de perceber a existência de narrativas pretensamente relacionadas a uma conjuntura artística, política e social e que apontam para um caminho de coletivização da obra, tendo em vista a sua confluência em relação à produção 
dos romancistas de 30 , formando parte do movimento espontâneo, expansivo ou diastólico, da forma como o caracteriza Holanda em "Fluxo e refluxo I" (1996, p. 334-335) ou como expressa Carvalhal sua perspectiva em relação à obra literária, entendendo-a como "uma concreção do geral, isto é, uma particularização do universal, na qual estão, ao mesmo tempo, o individual e o coletivo" (CARVALHAL, 2003, p. 33).

Neste trabalho, a fixação do relato de questões tocantes a um quadro social, ainda que nem sempre centrais, evidencia-se novamente. O factual, narrado nas Memórias, se transfigura no ficcional em um dos contos de Insônia (1947): "Um ladrão", publicado inicialmente, de acordo com Barros (2009), em 1939. Nos deteremos nesses dois registros e, para sua análise, nos pautaremos em estudos relativos a correntes mais recentes da literatura comparada, provenientes da concepção norte-americana inaugurada por René Wellek no final de 1950, porém não em relação à aproximação ao formalismo, mas sim à abertura no que diz respeito às possibilidades de estudos dentro dessa disciplina. A razão dessa especificação se deve ao fato de que, teoricamente, ela atende às necessidades dos textos em suas particularidades. São eles de um mesmo escritor e sistema literário, pertencentes a diferentes gêneros e tratando de uma ação sob perspectivas distintas. Para a abordagem discursiva e ideológica configurada no intrínseco e extrínseco de cada narrativa, nos apoiaremos na crítica sociológica, especialmente a influenciada por Antonio Candido.

Antes de nos atermos às leituras e análises dos textos de Graciliano Ramos, cabe outra delimitação a respeito da 
relação entre o relato memorialístico e a narrativa ficcional que pretendemos estudar, trata-se da questão da concepção e papel da memória. A respeito desta, Philippe Lejeune, em "Autobiografia e ficção", escreve sobre suas diferentes formas de abordagem.

Existem duas atitudes diametralmente opostas em relação à memória. Sabe-se que ela é uma construção imaginária, ainda que seja pelas escolhas que faz, sem falar de tudo o que inventa. Alguns optam por observar essa construção (fixar seus traços com precisão, refletir sobre sua história, confrontá-la a outras fontes...). Outros decidem continuá-la. Alguns freiam, outros aceleram, e todos vislumbram como resultado desse gesto o fantasma da verdade. E, consequentemente, ambos estão convencidos de que os outros estão enganados (LEJUNE, 2014, p. 123).

O "fantasma da verdade", aqui, não se configura como o cerne da questão. Se as memórias publicadas em 1953 possuem aspectos de uma criação, com a reconstituição de diálogos, cenas e espaços, não nos cabe analisar. O que nos compete é apreciar como se deu a "continuidade" dessa memória na escrita do romancista no exercício do conto e da reminiscência, partindo dos escritos memorialistas aos ficcionais e também destes àqueles.

Ao conceber que a literatura se configura como um vasto sistema de trocas (PERRONE-MOISÉS, 1990, p. 94), passamos a observar os câmbios realizados entre os textos, a discutir como um mesmo enredo foi abordado nas duas manifestações 
artísticas, sem qualquer ordem hierárquica. Perrone-Moisés, ao apresentar algumas propostas teóricas do século $X X$ que contribuíram para os estudos comparados, ponderou que:

[...] a literatura comparada não só admite, mas comprova que a literatura se produz num constante diálogo de textos, por retomadas, empréstimos e trocas. A literatura nasce da literatura; cada obra nova é uma continuação, por consentimento ou contestação, das obras anteriores, dos gêneros e temas já existentes. Escrever é, pois, dialogar com a literatura anterior e com a contemporânea (1990, p. 94).

Com o objetivo, então, de estudar o diálogo e a continuidade que se dá entre os textos em relação a personagens, ações e perspectivas discursivas, apresentam-se fragmentos dos objetos de análise, cujo enredo se resume na história de um homem na tentativa malograda de furtar uma residência. Seguindo a ordem das publicações, tem-se um breve trecho do conto "Um ladrão":

[...] O indivíduo a que me refiro ainda não tinha alcançado essa andadura indispensável e prejudicial: indispensável no interior das casas, à noite; prejudicial na rua, porque denuncia de longe o transeunte. Sem dúvida o homem suspeito não tem só isso para marcá-lo ao olho do tira: certamente possui outras pintas, mas é esse modo furtivo de esquivar-se como quem não toca o chão que logo caracteriza. O sujeito não sabia, pois, andar assim, e passaria despercebido na multidão. Por enquanto nenhuma esperança de 
se acomodar àquele ingrato meio de vida. E Gaúcho, o amigo que o iniciara, havia sido franco: era bom que ele escolhesse ocupação menos arriscada. Mas o rapaz tinha cabeça dura: animado por três ou quatro experiências felizes, estava ali, rondando o portão, como um técnico (RAMOS, 1994, p. 18).

A seguir, a reprodução do trecho de Memórias do cárcere, no qual Graciliano reproduz a narrativa de Gaúcho, homem que, ao contar seus feitos, entretinha e despertava a curiosidade do escritor. Observe-se que a interlocução se dá entre Gaúcho e Ramos.

[...] Como eu ia dizendo, o meu ajudante não prestava para nada. A última vez que me acompanhou endoideceu e nunca mais se levantou. Arrombei a porta, fomos à copa, achei um queijo, comemos uma banda; piquei o resto e despejei querosene em cima.

- Por quê?

- Por nada. Só para fazer miséria. Subimos uma escada. Na sala da frente estava dormindo um casal de velhos. No guarda-vestidos afanei uma carteira com grana e um bobo. Um bobo, sim senhor, um relógio. Andei na casa toda, que não é direito sair deixando gaveta fechada. No oratório havia muito santo, mas nessas coisas de religião eu não mexo. Enfim consegui muamba regular para o intrujão. No derradeiro quarto vimos uma lindeza com os peitos de fora. Aí o sujeito perdeu 
a ação, ficou besta, de olhos arregalados, como se estivesse diante de uma imagem do altar. Puxei a manga dele, chamei e tornei a chamar: "Vamos embora". Nem ouvia. De repente subiu na cama e deu um beijo na boca da moça. Calcule. Foi encanado e escrachado, natural. Larguei-me na escada abaixo, soltei a muamba, saí da casa, atravessei o jardim, pulei a grade. Felizmente salvei a carteira e o bobo (RAMOS, s.d., p. 378-379).

No conto, Graciliano Ramos utiliza-se da figura do ladrão desconhecido, que fora citado por Gaúcho no relato posteriormente registrado nas Memórias. Na narrativa de Insônia, esse episódio é reconfigurado e centralizado. $O$ antes e o depois, quase suprimidos da narrativa memorialística, estão presentes na composição ficcional, dando continuidade à memória ulteriormente recuperada.

\section{A PERSPECTIVA NARRATIVA NA APROXIMAÇÃO E DISTANCIAMENTO DAS PERSONAGENS}

Divergindo do contar desapegado de Gaúcho na obra de 1953 - no sentido de não oferecer informações detalhadas e subjetivas a respeito das personagens envolvidas na ação e da ação em si - observamos que o narrador do conto se achega à personagem inábil citada nas Memórias, acompanha-a detidamente em seus atos e incertezas. O escritor amplia a performance dessa figura, sem deixar, ao início do conto, de situar o leitor à caracterização sumária dada a esta em Memó- 
rias do cárcere.

Em seu artigo "A grande angular em Mário de Andrade, a objetiva de Ramos: uma observação dos contos 'O ladrão', de Mário de Andrade, e 'Um ladrão', de Graciliano Ramos”, Barros (2009) trata dessa perspectiva narrativa aproximada à personagem central, empregada pelo romancista no conto, indicando, em sua análise, um tal acercamento que leva a possibilidade de confundir ou fundir a voz do narrador à voz da personagem central.

O foco narrativo é uma das grandes diferenças entre os dois textos. Ao analisarmos o relato de Gaúcho dentro da narrativa memorialística, notamos a utilização do discurso direto dentro de um texto cujo foco narrativo pode ser expresso a partir da noção de narrador-protagonista - segundo a nomenclatura e tipologia de Friedman (2002). Caso estabelecêssemos um recorte do relato de Gaúcho como independente do todo, teríamos um outro narrador, e não apenas personagem, também protagonista, "quase que inteiramente limitado a seus próprios pensamentos, sentimentos e percepções" (FRIEDMAN, 2002, p. 177).

$\mathrm{Na}$ ficção, a aproximação do leitor a uma personagem sem outros interlocutores que não ela mesma, em algumas passagens, dá lugar a um narrador predominantemente onisciente neutro - com apenas um índice de primeira pessoa em: o "indivíduo a que me refiro ainda não tinha alcançado essa andadura indispensável e prejudicial [...]" (RAMOS, 1994, p. 18). Delimitar o que é reflexão do narrador ou da personagem em alguns trechos é complexo em virtude da ausência de diálogos como os constantes nas Memórias e da mistura 
de discursos presentes no texto, como se vê, por exemplo, no primeiro período desta passagem: "Apesar de ter alcançado o meio da escada, achava difícil continuar a viagem. E se alguém estivesse a observá-lo no escuro?" (RAMOS, 1994, p. 25). A mudança da perspectiva narrativa atende às necessidades de cada objeto e permite a continuidade da ação por caminhos diversos. A diferenciação do modo como se afiguram as personagens deve-se também à adoção do foco narrativo. Nas Memórias, percebemos o ladrão a partir do olhar de outro. Em: "Foi um pivete muito ordinário, e quando cresceu, chegou a descuidista, não passou a ventanista" (RAMOS, s.d., p. 377) e em outros trechos, temos uma figura que não se constrói no decorrer dos fatos, mas nos é dada por Gaúcho. Os meios de informação utilizados por este narrador são as suas percepções. Ainda que no centro da ação, Gaúcho nos distancia da figura que apresenta ao, por exemplo, praticamente não lhe ceder a voz e concentrar em si a perspectiva narrativa. Isso, certamente, pelo próprio caráter do relato no qual o seu contar está configurado, propício ao predomínio do sumário narrativo (FRIEDMAN, 2002, p. 172), ou do relato generalizado, o contar de fato, coerente com o referente da conversação.

Em “Um ladrão”, a personagem é (des)construída. Iniciou como indivíduo (RAMOS, 1994, p. 18), mas, quando "os dentes bateram castanholas", soou como porco zangado (1994, p. 23); "feito um macaco" (1994, p. 24) ficaria pendurada se necessário; ao ter um acesso de tosse, produziu um "resfolegar de cachorro novo" (1994, p. 29) e, por fim, desprovida de racionalização, acabou transformada "em mosca" (1994, p. 33) girando em torno da vítima. Diferente, ademais, é o desta- 
que de aspectos típicos de cenas que se manifestam nos "detalhes sucessivos e contínuos de tempo, lugar, ação, personagem" (FRIEDMAN, 2002, p. 172) e, embora sem diálogos, essa condição fornece ao leitor pormenores que atuam como forma para acessar a personagem central, aproximando-nos a ela e diferindo do distanciamento estabelecido no relato pelo ângulo de visão empregado.

Essa última questão pode ser controversa ao refletirmos sobre o discurso natural expresso por Gaúcho no tratamento de questões como o furto, pois, se o seu enunciado não nos fornece detalhes, podemos conjecturar a existência do entendimento, por parte dessa figura, de que seu interlocutor possuísse noções já não distantes sobre o tema, sendo por isso dispensável minúcias como as que figuram no conto. A aparente despreocupação com pormenores na narrativa memorialística pode não familiarizar o leitor à personagem que se tornou principal na ficção, todavia, permite denotar uma aproximação desses tipos por meio de uma espécie de compartiIhamento de mundos. Outro ponto nesse sentido que também se oferece contraditório é a adoção do artigo indefinido utilizado no título em "Um ladrão", demonstrando indiferença não só em relação a uma identidade como também a uma existência. Ao mesmo tempo em que a mudança de perspectiva narrativa parece trazer a personagem para o primeiro plano, a sua designação a mantém em um patamar alheio, embora sujeita à identificação enquanto transgressora.

Voltando à questão da continuidade pontuada por Lejeune em relação à memória e por Perrone-Moisés em relação à literatura, observa-se que Graciliano Ramos segue na mes- 
ma direção no tocante às atitudes e singularidades da personagem. O relato memorialístico converge com o ficcional, mas este vai além por outro caminho, o da particularização ou aproximação, ainda que com a indolência da falta de um nome próprio ou da indefinição do substantivo que confere à figura inábil uma identificação. $O$ "ir além", neste contexto, com o significado concreto de ampliação das ações e pormenores subjetivos.

\section{O CONFLITO ENTRE CLASSES}

Na análise comparativa de Barros (2009), há a observação da relação conflituosa entre as classes dispostas na narrativa ficcional. Ao analisarmos os dois textos, a consciência e latência dessa hostilidade no trecho do relato memorialístico não se evidencia tanto quanto no conto, e isso em razão, presume-se, da naturalidade no discurso de Gaúcho. O conflito, na ficção, pode ser expresso pelas diferentes formas de caracterização dos moradores da casa, como se vê, por exemplo, no momento em que a figura central os percebe: "avistou um braço caído fora da cama. Braço de velha, braço de velha rica, de uma gordura nojenta. A mão era papuda e curta, anéis enfeitavam os dedos grossos" (RAMOS, 1994, p. 27); e, nas Memórias, as referências: "Subimos uma escada. Na sala da frente estava dormindo um casal de velhos", "No derradeiro quarto vimos uma lindeza com os peitos de fora" (RAMOS, s.d., p. 378). A primeira descrição, longe da imparcialidade, ganha contornos de repulsa e novamente de apartamento entre sujeito e lugar, sujeito e leitor e sujeito e sociedade. 
Existe um afastamento concreto entre as classes e a forma de exploração do espaço em "Um ladrão", que pode pontuar também essa questão. Novamente o artigo indefinido surge como um possível índice revelador da indiferença no que se refere a um sujeito marginalizado. A habitação do espaço "casa" por parte da personagem central, na ficção, se dá em dois momentos: quando lá trabalha, como consertador de fogões, e quando lá retorna a fim de furtar e fazer, ele também, a sua pequena fortuna.

Em Memórias do cárcere, o feito de Gaúcho é um entre muitos: "E Gaúcho [...] estendia-se por mais um de seus numerosos casos" (RAMOS, s.d., p. 379), o que converge com o seu discurso e diverge da ação do seu companheiro, tipo pertencente ao universo socialmente desclassificado e que se mostra no conto por intermédio da relação com o meio. Essa observação pode ser expressa no constante desconforto da personagem com o externo e com as figuras que a rodeiam. Vejamos:

Encolheu-se mais, olhou a janela do prédio fronteiro, imaginou que por detrás da janela alguém o espreitava, talvez o dono da loja de fazenda que o examinara com ferocidade, através dos óculos, quando ele estacionara junto ao balcão (RAMOS, 1994, p. 22).

Aqui, a inadequação ao espaço se soma à relação conflituosa com outros tipos. Há momentos em que é clara a presença de ambientes impróprios para alguns, como: "Passava da meia-noite. Felizmente a rua topava o morro e só tinha uma entrada. À exceção dos moradores, pouca gente devia ir ali" 
(RAMOS, 1994, p. 21). Esse distanciamento está, nas Memórias, subentendido por todo o contexto; no conto, o narrador o evidencia por outros meios, pormenorizando possivelmente o que no relato estava naturalizado e pressuposto.

\section{"OS NORDESTINOS TÊM ESCRITO INCONVENIÊNCIAS"}

Em "Norte e Sul" (RAMOS, 2015, p. 191-193), texto de 1937, Graciliano Ramos contestou a distinção estabelecida, então, entre os escritores do Norte e do Sul do Brasil. Ele não negou a existência de uma diferenciação, mas não de caráter geográfico, e sim no tocante à forma e aos assuntos dos romances. Ao projetar Memórias do cárcere, o escritor evidenciou ao filho Júnio Ramos, em carta de outubro de 1945, o objetivo de retratar as prisões de 1936. Na época, escreveu:

[...] tenciono apresentar aquela gente em cuecas, sem muitos disfarces, com os nomes verdadeiros. Necessito a autorização das personagens: não tenho o direito de utilizar gente viva num livro de memórias que encerrará talvez inconveniências (RAMOS, 2011, p. 285).

Como observamos, esse movimento em relação à abordagem de questões sociais foi operado em outras composições, unindo texto e contexto. Desde São Bernardo (1934), a dinâmica da narrativa parece acompanhar o pragmatismo das escolhas de Paulo Honório, assim como, aqui, o diálogo de Gaúcho, na obra póstuma, conflui com algo que talvez possamos definir como alienação social, tal qual a encontramos na perspectiva marxista. Nessa mesma direção, o caminho da 
personagem de "Um ladrão" nos permite acompanhá-la por meio do foco narrativo escolhido, colocando-nos na posição do intruso em um espaço socialmente "inadequado".

Graciliano Ramos, com seus temas e formas de desenvolvê-los, ofereceu a concretização da abordagem sociológica. Nessa perspectiva, ao haver fixado questões sociais em suas narrativas, o escritor abriu sua produção artística para uma leitura em interação e totalidade, já que, sobre a prevalência da forma ou do contexto "a integridade da obra não permite adotar nenhuma dessas visões dissociadas; [...] só a podemos entender fundindo texto e contexto numa interpretação dialeticamente íntegra" (CANDIDO, 1980, p. 4).

$\mathrm{E}$, se concebermos a história, ou conjuntura, ou temática pertencente a esta como uma forma de manifestação cultural, entenderemos, na disposição desta análise, que "a literatura é uma prática intelectual que, sem deixar de ter no literário o seu objeto, confronta-o com outras formas de expressão cultural" (CARVALHAL, 2003, p. 48), o que não só expande o fenômeno literário para outros campos do saber, como também amplia esses campos para reflexões heterogêneas. "É, portanto, um procedimento, uma maneira específica de interrogar os textos literários não como sistemas fechados em si mesmos, mas em sua interação com outros textos" (CARVALHAL, 2003, p. 48). 


\section{REFERÊNCIAS BIBLIOGRÁFICAS}

BARROS, Maria Luzia Carvalho. A grande angular em Mario de Andrade, a objetiva de Ramos: uma observação dos contos "O ladrão", de Mário de Andrade, e "Um ladrão", de Graciliano Ramos. Revista Crioula, São Paulo, nov. 2009. Seção Artigos \& Ensaios. Disponível em: http://www.revistas.usp.br/ crioula/article/view/54983. Acesso em: 03 dez. 2016.

CANDIDO, Antonio. Ficção e confissão: ensaios sobre Graciliano Ramos. 3.ed. Rio de Janeiro: Ouro sobre Azul, 2006.

- Literatura e sociedade: estudos de teoria e história literária. 6.ed. São Paulo: Ed. Nacional, 1980.

CARVALHAL, Tania Franco. O próprio e o alheio: ensaios de literatura comparada. São Leopoldo: Ed. Unisinos, 2003.

FRIEDMAN, Norman. O ponto de vista na ficção: o desenvolvimento de um conceito crítico. In: Revista USP, São Paulo, março/maio 2002. Seção Arquivo. Disponível em: http://www. revistas.usp.br/revusp/article/view/33195/35933. Acesso em: 14 março 2017.

HOLANDA, Sérgio Buarque de. Fluxo e Refluxo - I. In: O espírito e a letra: estudos de crítica literária, 1948-1959: volume II. São Paulo: Companhia das Letras, 1996. 
LAFETÁ, João Luiz. 1930: a crítica e o Modernismo. São Paulo: Duas Cidades; Ed. 34, 2000.

LEJEUNE, Philippe. Autobiografia e ficção. In. . O pacto autobiográfico: de Rousseau à internet. Belo Horizonte: Editora UFMG, 2014.

PERRONE-MOISÉS, Leyla. Literatura comparada, intertexto e antropofagia. In.__. Flores da escrivaninha: ensaios. São Paulo: Companhia das Letras, 1990.

RAMOS, Graciliano. Cartas. 8.ed. Rio de Janeiro: Record, 2011.

. Correspondência ativa - Arquivo IEB-USP. Fundo GR-CA-06. Doado em 1980 por Heloísa Ramos.

. Memórias do cárcere (2 vols.). São Paulo: Círculo do Livro, s. d.

. Norte e Sul. In: . Linhas tortas. 22.ed. Rio de Janeiro: Record, 2015. . Um ladrão. In. . Insônia. 24.ed. São Paulo: Record, 1994.

Submissão: 2017-02-05

Aceite: 2017-04-14 